\title{
A CONCRETIZAÇÃO DO DIREITO À SAÚDE PELA JURISPRUDÊNCIA DO SUPREMO TRIBUNAL FEDERAL
}

\author{
José dos Santos Carvalho Filho ${ }^{1}$ \\ Simone Letícia Severo e Sousa Dabés Leão ${ }^{2}$
}

RESUMO: O artigo analisa a concretização do direito à saúde por atuação do Supremo Tribunal Federal. A saúde é direito de todos e dever do Estado, o que requer financiamento público para efetivação. Todavia, a precariedade do sistema público de saúde, a ausência de recursos e o descumprimento de políticas públicas conduzem à judicialização da saúde, fenômeno que gera impacto substancial nos programas de governo, de modo que é preciso estabelecer um ponto de equilíbrio entre a efetivação judicial desse direito e as limitações orçamentárias do Estado. O trabalho explora metodologia qualitativa, do tipo exploratória, por coleta de dados.

PALAVRAS-CHAVE: Direito à Saúde. Intervenção Judicial. Jurisprudência. Supremo Tribunal Federal. Reserva do possível.

\section{THE IMPLEMENTATION OF THE RIGHT TO HEALTH BY BRAZILIAN SUPREME COURT}

\begin{abstract}
This article analyzes the implementation of the right to health by Brazilian Supreme Court. The right to health is established as fundamental right and duty of the State, which implies positive obligations that may only be fulfilled by public funds. Since the Brazilian context faces a precarious public health system, the lack of resources and the disrespect of public policies lead to an increase in judicialization. Consequently, the government programs are strongly impacted. It is, therefore, necessary to establish a balance between the right to health and the budgetary limitations, to identify parameters for the judicial implementation of this right.
\end{abstract}

KEY WORDS: Right to health. Judicial Review. Jurisprudance. Supremo Tribunal Federal. The cost of rights.

\footnotetext{
${ }^{1}$ Pós-doutorando do programa de direitos sociais da Universidade de Salamanca (Espanha). Doutor em direito público no Institut d'Études Politiques dAix-en-Provence (Sciences-PO Aix) / Aix-Marseille Université (França), com diploma reconhecido no Brasil pela Universidade de São Paulo (USP). Mestre em Direito Constitucional. Autor de livros e de vários textos científicos nas áreas de direito constitucional e direito processual civil. Professor das disciplinas processo constitucional e direito e cinema na Escola de Direito de Brasília. Assessor de Ministro do Supremo Tribunal Federal. Editor do Observatório da Jurisdição Constitucional. E-mail: jscarvalhofilho@gmail.com

${ }^{2}$ Pós-doutoranda em Direitos Sociais na Universidade de Salamanca-Espanha. Doutora em Direito Público. Mestre em Direito (Relações econômico-empresariais). Professora Universitária. Assessora Judiciária TJMG. Email: simoneleticia77@gmail.com
} 


\section{INTRODUÇÃO}

O conceito de saúde, segundo definição apresentada pela Organização Mundial de Saúde, "é um estado de completo bem-estar físico, mental e social e não apenas a ausência da doença ou enfermidade". (OMS, 1946). Um dos maiores desafios enfrentados pela sociedade brasileira é a concretização do direito à saúde.

A saúde, enquanto direito social constitucionalmente garantido, qualifica-se como direito fundamental que assiste a todas as pessoas como condição ou consequência indissociável do direito à vida. Nos termos do art. 196 da Constituição de 1988, a saúde é direito de todos e dever do Estado, garantido mediante políticas sociais e econômicas que visem à redução do risco de doenças e outros agravos, e ao acesso universal e igualitário às ações e serviços para sua promoção, proteção e recuperação.

Evidencia-se que a Constituição Federal de 1988 erigiu os direitos sociais à categoria de direitos fundamentais, ao incluí-los, expressamente, no Título II, "Dos Direitos e Garantias Fundamentais", por isso, esses direitos também estão sujeitos ao que determina o art. $5^{\circ}, \S 1^{\circ}$, da CF, que prevê a aplicação imediata das normas definidoras dos direitos e garantias fundamentais.

Em determinados contextos, o Estado vem se mostrando ineficaz e por vezes totalmente omisso em relação à proteção à saúde no Brasil. Diante da precariedade do sistema brasileiro público de saúde, aliada ao número insuficiente de fornecimento de medicamentos e/ou tratamentos médicos e de procedimentos cirúrgicos, surge a denominada judicialização da saúde, tendo em vista que o cidadão sem condições financeiras procura socorrer-se no Judiciário em busca dos seus direitos.

Nessa conjuntura, a problemática da pesquisa reside em saber em que medida o Estado-administrador pode ser condenado pelo Estado-juiz a fornecer medicamento e/ou tratamento hospitalar a cidadãos necessitados, com fundamento no direito constitucional à saúde. A judicialização da saúde tem demonstrado ser uma alternativa necessária para conter as omissões abusivas dos entes federados. Isso porque o direito à saúde reclama, quanto à sua efetivação, um mínimo de concretização (mínimo existencial), que nem sempre é implementado.

Nesse contexto, a reflexão se inicia com uma breve análise do Direito à Saúde na Constituição Federal de 1988. Em seguida, pondera-se acerca do fornecimento de 
medicamentos, com enfoque especial nos medicamentos não padronizados pelo SUS, os de alto custo, aqueles não registrados pela ANVISA e o uso "off label" de medicamentos. A análise jurisprudencial do Supremo Tribunal Federal nesse ponto contribui para melhor compreender como o fenômeno da judicialização se operacionaliza no contexto brasileiro, notadamente no que se refere à atuação do juiz constitucional na implementação do direito social à saúde.

Ao final, busca-se entrelaçar o debate sobre acesso à saúde com o tema da intervenção judicial, a partir das considerações desenvolvidas.

\section{O DIREITO SOCIAL À SAÚDE NA CONSTITUIÇÃO FEDERAL DE 1988.}

A valorização do direito à saúde deve-se essencialmente ao fato de ser um direito fundamental do homem, considerando-se que a saúde é "um dos principais componentes da vida, seja como pressuposto indispensável para sua existência, seja como elemento agregado à sua qualidade. Assim, a saúde se conecta ao direito à vida” (SCHWARTZ, 2001, p. 52).

No direito comparado, a garantia do direito à saúde ao cidadão só apareceu 40 anos após a Declaração Universal dos Direitos Humanos e no Brasil foi somente a partir da terceira Constituição, em 1934, que se começou a falar em saúde nas Constituições Federais Brasileiras.

No Brasil, em 1977, foi criado o INAMPS (Instituto Nacional de Assistência Médica da Previdência Social), para atendimento exclusivo às pessoas que possuíam carteira de trabalho. E em 1979 foi implantado o PIASS (Programa de Interiorização das Ações de Saúde e Saneamento), tendo em 1980 um processo de expansão de cobertura.

Em 27 de julho de 1993, quase três anos após a promulgação da Lei n. 8.080/90, que regulamentou o SUS, o INAMPS foi extinto pela Lei n. 8.689 de 27.7.1993, sendo suas funções, competências, atividades e atribuições absorvidas pelas instâncias federal, estadual e municipal do SUS.

As Constituições Brasileiras anteriores a 1988 não garantiam o direito à saúde. No máximo, cabia ao Estado cuidar da assistência pública e da prestação de assistência médica e hospitalar ao trabalhador filiado ao regime previdenciário. 
A partir dos anos 80, mudanças econômicas e políticas ocorridas no país passaram a exigir a substituição do modelo médico-assistencial privativista por outro modelo de atenção à saúde. Foi então criado o Programa Nacional de Serviços Básicos de Saúde (PREV-SAÚDE), que, na realidade, nunca passou de mero projeto (MARTINS, 2008, p. 46).

A política de saúde no Brasil seguiu, nos anos 80 (século XX), uma trajetória paradoxal: de um lado, a concepção universalizante, de outro, obedecendo às tendências estruturais organizadas pelo projeto neoliberal, concretizam-se práticas caracterizadas pela exclusão social e redução de verbas públicas. Em função dos baixos investimentos em saúde e consequente queda da qualidade dos serviços, ocorreu uma progressiva migração dos setores médios para os planos privados de saúde. O mercado foi se expandindo e, em 1988, a Constituição Federal, além de estabelecer a atribuição do Estado de assegurar o direito à saúde dos cidadãos pela criação de um sistema nacional de saúde, garantiu o setor de assistência médico-hospitalar, permitindo a oferta de serviços de assistência à saúde pela iniciativa privada, sob o controle do Estado.

Enquanto as Constituições anteriores trataram dos direitos sociais de maneira tímida, a Constituição Federal de 1988 inovou, ao estabelecer a saúde como direito de todos e dever do Estado, conferindo aplicabilidade direta e exequibilidade imediata às normas constitucionais. ${ }^{3}$ A Constituição Federal de 1988, seguindo a concepção contemporânea de direitos humanos, inseriu no texto constitucional um rol de princípios e direitos sociais não abordados pelas Constituições anteriores. Evidencia-se, portanto, que a Constituição cidadã rompe com a tradição liberal, dando efetiva atenção à saúde, ao incluí-la como direito social da pessoa humana, conforme o disposto nos arts. $6^{\circ}$ e 196, segundo os quais a saúde é direito de todos e dever do Estado.

Ademais, ao dispor sobre a organização político-administrativa dos entes federados, estabelece, no seu artigo 23, a competência comum entre a União, Estados, Distrito Federal e Municípios para cuidar da saúde e da assistência pública. Desse modo, pode-se afirmar que, somente em 1988, a saúde foi tratada como um direito inerente ao cidadão.

\footnotetext{
${ }^{3}$ Explica-se: a Constituição Federal foi um marco para a redefinição das prioridades da política do Estado na área da saúde pública, concebendo o SUS como a maior política de inclusão social implantada sob o regime democrático no Brasil, com fundamento na própria Carta, regulamentada via delegação constitucional pela Lei. n. 8.090/90, pela Lei Orgânica de Saúde, pela Lei n. 8.142/91, que organiza as deliberações administrativas, assim como pela Lei Complementar n. 141/2012, que dispõe sobre o financiamento do sistema. (DRESCH, 2019 , p. 5)
} 
O direito à vida está contemplado na Constituição Federal de 1988 no título "Dos Direitos e Garantias Fundamentais", sendo consagrado como o mais fundamental dos direitos, uma vez que é dele que derivam todos os demais. A Constituição estabelece, ainda, no art. 196, que a saúde é dever do Estado, norma de aplicação e efeito imediatos. Além disso, prevê, no art. 199, que o setor privado exerça a assistência à saúde, criando uma solidariedade no seu exercício entre o Poder Público e o setor privado.

Nessa conjuntura, a Constituição de 1988 incorpora claramente esse caráter do direito à saúde, ao estabelecer, que ele será "garantido mediante políticas sociais e econômicas que visem à redução do risco de doenças e de outros agravos e ao acesso universal e igualitário às ações e serviços para sua promoção, proteção e recuperação".

A saúde consta como um dos direitos sociais previstos no art. $6^{\circ}$, que abre o Capítulo II ('Dos Direitos Sociais') do Título II ('Dos Direitos Fundamentais') da Constituição de 1988. Além disso, o caput do art. 196, já referido, define a saúde como direito de todos e dever do Estado. Portanto, o embasamento constitucional à garantia do direito à saúde no Brasil encontra-se no artigo $6^{\circ}$ da Constituição de 1988, cujo rol elenca os chamados direitos sociais, da seguinte forma: "São direitos sociais a educação, a saúde, o trabalho, a moradia, o lazer, a segurança, a previdência social, a proteção à maternidade e à infância, a assistência aos desamparados, na forma desta Constituição".

A Constituição prevê um regime de cooperação entre a União, os Estados e os Municípios, que devem concorrer para incrementar o atendimento à saúde da população. Cada uma dessas esferas de governo, que deve agir em concurso e de forma solidária, uma suplementando a outra, tem sua competência administrativa estabelecida na Lei 8.080/90. (CARVALHO, 2012, p. 817).

A Lei Orgânica da Saúde (Lei 8.080/90) implantou amplamente o Sistema Único de Saúde, enquanto a Lei 9.656/98, que trata da regulamentação dos Planos de Saúde, visou equilibrar as relações contratuais (saúde suplementar no Brasil). Posteriormente, a Lei Complementar 141/2012 veio a regular também novas normas do SUS, dispondo sobre os percentuais mínimos a serem aplicados pelos entes públicos na saúde pública.

Até a promulgação da Lei 9.656, de 28 de janeiro de 1998, que definiu as regras para o funcionamento do setor de saúde suplementar, o Estado Brasileiro não dispunha dos instrumentos necessários para a regulação dos planos privados de assistência à saúde, que já funcionavam há décadas no país. 
Registre-se que, no contexto histórico brasileiro, principalmente a partir da década de 1990, o Estado passa a adotar medidas para se desresponsabilizar completamente pela promoção de saúde, transferindo a sua tutela para as mãos da iniciativa privada, com financiamento do Estado. A criação da Agência Nacional de Saúde Suplementar (ANS) pela Medida Provisória 2.012-2, de 30 de dezembro de 1999, convertida na Lei 9.961, de 28 de janeiro de 2000, resultou da exigência da sociedade para a necessidade de se regular uma atividade complexa, inserida num setor essencial, que é a saúde, trazendo nova dinâmica para esse segmento.

De todo modo, a saúde continua sendo um bem prioritário para o povo brasileiro, além de condição sine qua non de cidadania - aqui entendida como vida de forma digna, segura e produtiva. A garantia de saúde está incluída na ideia de segurança, assim como a garantia de um mínimo de segurança é condição essencial à existência de liberdade (BAHIA, C. J. A.; ABUJAMRA, A. C. P, 2005, p. 39).

Diante de todas essas considerações, evidencia-se que cabe ao Estado a função de implementar e efetivar as políticas públicas que garantem a efetividade dos direitos sociais, com prestações positivas em prol da coletividade.

\section{DO FORNECIMENTO DE MEDICAMENTOS.}

Estabelecida nos artigos $6^{\circ}$ e 196 da Constituição Federal (BRASIL, 1988), a garantia do direito à saúde se tornou dever do Estado, mas sua concretização envolve questões políticas, econômicas, orçamentárias, tecnológicas, sociais, culturais e jurídicas que, conjugadas entre si, permitem vislumbrar seus desafios (VENTURA et al., 2010, p. 78).

O fenômeno da denominada judicialização da saúde ou judicialização das políticas públicas de saúde, possui uma dinâmica na qual o Poder Judiciário se substitui ao Poder Executivo na escolha do medicamento/tratamento a ser fornecido, ao fundamento de que a efetivação do direito à saúde está assegurada constitucionalmente. Ocorre que esse fenômeno acarreta risco de subversão do sistema regulado das políticas públicas (DRESCH, BICALHO, 2019, p. 94).

No que tange ao fornecimento de medicamentos, deve-se observar o arcabouço jurídico que envolve a prestação do direito à saúde, inclusive os princípios constitucionais, de

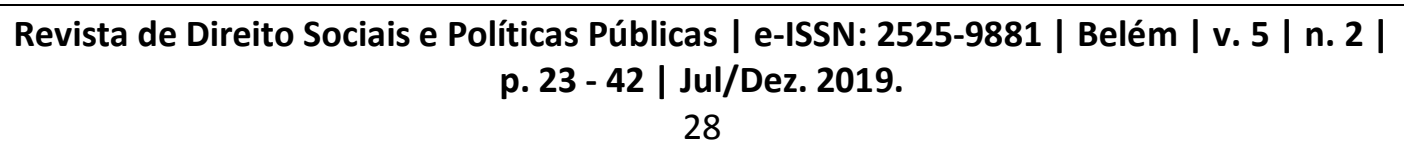


forma a garantir que o direito fundamental de acesso à saúde seja, na medida do possível, devidamente implementado.

A promoção da saúde é um dever do Estado, realizado conforme a Lei 8.080/90, que estabelece o SUS (Sistema Único de Saúde), dispondo, em seu $§ 1^{\circ}$, do artigo $5^{\circ}$ :

O dever do Estado de garantir a saúde consiste na formulação e execução de políticas econômicas e sociais que visem à redução de riscos de doenças e de outros agravos e no estabelecimento de condições que assegurem acesso único e igualitário às ações e aos serviços para a sua promoção, proteção e recuperação.

O SUS é considerado o sistema de saúde mais avançado no mundo. Entretanto, a prática é um tanto diversa da legislação e, infelizmente, o SUS não funciona como deveria.

No que tange à prestação dos serviços de saúde, a Constituição não especificou qual esfera do poder deverá executá-los, inferindo-se que a saúde, enquanto dever do Estado, é responsabilidade de todos os entes federados. Desse modo, compete à União, ao Distrito Federal, aos Estados e aos Municípios, prestar assistência à saúde.

A judicialização da saúde envolve diversas dificuldades, que dizem respeito a vários princípios e valores constitucionais, como dignidade da pessoa humana (conceito do mínimo existencial), isonomia (cidadãos que ajuízam ações seriam mais beneficiados do que os que apenas se submetem ao SUS), princípio da equidade (as políticas públicas partem de um ideal de Justiça distributiva, cuja finalidade é assegurar tratamento igual aos cidadãos iguais, e desigual aos desiguais), separação dos poderes (Judiciário atuando em questões públicas), princípio federativo (responsabilidade de cada ente federado), universalidade e integralidade, e culminam no princípio da reserva do possível (de modo a assegurar que as demandas judiciais individuais ou coletivas não comprometam a política pública de saúde existente) (VALLE; CAMARGO, 2010; PEREIRA, 2012).

A jurisprudência do Supremo Tribunal Federal já está consolidada no sentido de que todos os entes da Federação são solidariamente responsáveis pelo cumprimento das obrigações atinentes à saúde. Esse entendimento foi definido, inicialmente, no julgamento da Suspensão de Tutela Antecipada 175, Rel. Min. Gilmar Mendes, Tribunal Pleno, Dje de 30/4/2010, cujo acórdão possui a seguinte ementa:

Suspensão de Segurança. Agravo Regimental. Saúde pública. Direitos fundamentais sociais. Art. 196 da Constituição. Audiência Pública. Sistema 
Único de Saúde - SUS. Políticas públicas. Judicialização do direito à saúde. Separação de poderes. Parâmetros para solução judicial dos casos concretos que envolvem direito à saúde. Responsabilidade solidária dos entes da Federação em matéria de saúde. Fornecimento de medicamento: Zavesca (miglustat). Fármaco registrado na ANVISA. Não comprovação de grave lesão à ordem, à economia, à saúde e à segurança públicas. Possibilidade de ocorrência de dano inverso. Agravo regimental a que se nega provimento. (BRASIL. Supremo Tribunal Federal, 2010).

Mais recentemente, a Suprema Corte reiterou sua jurisprudência em recurso extraordinário com repercussão geral, para assentar que os entes federados têm responsabilidade solidária no fornecimento de medicamentos e tratamentos de saúde. Tal decisão foi tomada no julgamento do RE-RG 855.178, Rel. Min. Luiz Fux, oportunidade em que foi fixada a seguinte tese para o Tema 793 da Repercussão Geral:

\footnotetext{
Os entes da federação, em decorrência da competência comum, são solidariamente responsáveis nas demandas prestacionais na área da saúde, e diante dos critérios constitucionais de descentralização e hierarquização, compete à autoridade judicial direcionar o cumprimento conforme as regras de repartição de competências e determinar o ressarcimento a quem suportou o ônus financeiro (BRASIL. Supremo Tribunal Federal, 2019).
}

Observa-se, todavia, que a tese fixada, a despeito de reconhecer responsabilidade solidária dos entes federativos, determina também o ressarcimento a quem suportou o ônus financeiro, conforme as regras de repartição de competências estabelecida na legislação de regência.

Ocorre que essa questão, já pacificada, ilustra um problema apenas ligado à judicialização da saúde, consubstanciado em saber qual ente federativo é responsável pelo fornecimento de medicamento/tratamento, bem como quem deve arcar com os custos financeiros desse fornecimento. Há inúmeras outras problemáticas atinentes ao tema que são apresentadas nas linhas que seguem, como as questões afetas ao fornecimento de medicamentos não padronizados pelo SUS, fármacos não registrados pela ANVISA, uso "off label" de medicamentos e remédios de alto custo.

2.1 Medicamentos não padronizados pelo SUS, medicamentos não registrados pela ANVISA e o uso "off label" de medicamentos. 
Em relação aos medicamentos não padronizados pelo SUS, não registrados pela ANVISA e ao uso "off label" de fármacos, o Superior Tribunal de Justiça, definiu, no julgamento dos Embargos de Declaração no Recurso Especial 1.657.156 (Tema 106 da sistemática dos recursos repetitivos), Rel. Min. Benedito Gonçalves, as condições para o seu recebimento pelo Estado. Eis os requisitos:

i) Necessidade de registro na ANVISA;

ii) Demonstração de que o paciente tenha buscado alternativas disponíveis no SUS, comprovando a ineficácia dessas alternativas;

iii) Comprovação, mediante atestado médico da necessidade do medicamento pleiteado;

iv) Justificação da incapacidade econômica de prover tal medicamento.

A tese fixada no julgamento desse processo paradigmático restou assim formulada:

\begin{abstract}
A tese fixada no julgamento repetitivo passa a ser: A concessão dos medicamentos não incorporados em atos normativos do SUS exige a presença cumulativa dos seguintes requisitos: i) Comprovação, por meio de laudo médico fundamentado e circunstanciado expedido por médico que assiste o paciente, da imprescindibilidade ou necessidade do medicamento, assim como da ineficácia, para o tratamento da moléstia, dos fármacos fornecidos pelo SUS; ii) incapacidade financeira de arcar com o custo do medicamento prescrito; iii) existência de registro do medicamento na ANVISA, observados os usos autorizados pela agência. Modula-se os efeitos do presente repetitivo de forma que os requisitos acima elencados sejam exigidos de forma cumulativa somente quanto aos processos distribuídos a partir da data da publicação do acórdão embargado, ou seja, 4/5/2018 (BRASIL. Superior Tribunal de Justiça. 2018).
\end{abstract}

Diante dessas considerações, observa-se que o Superior Tribunal de Justiça definiu algumas premissas necessárias ao fornecimento de medicamento de alto custo pelo Estado, como inexistência de outro medicamento incorporado ao SUS que tenha a mesma eficiência terapêutica que o medicamento pleiteado e o seu efetivo registro na ANVISA, o que obstava o fornecimento de medicamento para uso off label.

Segundo a ANVISA, o uso off label é definido como a indicação do medicamento de maneira distinta daquela autorizada pelo órgão regulatório de medicamentos em um país. Em outros termos, o medicamento é utilizado para uma indicação terapêutica não descrita no rótulo ou bula, podendo também estar relacionado ao uso em uma faixa etária diferente da indicada, além de outra via de administração, dose e/ou frequência de uso. Em geral, ocorre quando ainda não existem bases científicas adequadas justificando esse uso. 
Em que pese a importância de se considerar o medicamento dentro do contexto da medicina baseada em evidência, não há vedação legal à prescrição de medicamento registrado na ANVISA para indicação diversa daquela para a qual foi aprovada ${ }^{4}$ (DRESCH, BICALHO, 2019, p. 45-46). Não obstante, nos termos do referido julgamento do Superior Tribunal de Justiça, não é permitido o fornecimento de medicamento off label. A propósito, a Corte acolheu parcialmente embargos de declaração opostos pelo Estado do Rio de Janeiro para fazer prestar esse esclarecimento em sua decisão.

No que diz respeito à jurisprudência do Supremo Tribunal Federal, houve uma modificação desse entendimento, na medida em que a Corte permitiu o fornecimento excepcional de medicamento não registrado na ANVISA. Na Sessão de Julgamento de 22/5/2019, o Plenário do STF julgou o RE-RG 657.718, Rel. Min. Marco Aurélio, para fixar a seguinte tese em regime de repercussão geral (Tema 500):

O Estado não pode ser obrigado a fornecer medicamentos experimentais. 2. A ausência de registro na ANVISA impede, como regra geral, o fornecimento de medicamento por decisão judicial. 3. É possível, excepcionalmente, a concessão judicial de medicamento sem registro sanitário, em caso de mora irrazoável da ANVISA em apreciar o pedido (prazo superior ao previsto na Lei $\mathrm{n}^{\circ}$ 13.411/2016), quando preenchidos três requisitos: (i) a existência de pedido de registro do medicamento no Brasil (salvo no caso de medicamentos órfãos para doenças raras e ultrarraras);(ii) a existência de registro do medicamento em renomadas agências de regulação no exterior; e (iii) a inexistência de substituto terapêutico com registro no Brasil. 4. As ações que demandem fornecimento de medicamentos sem registro na ANVISA deverão necessariamente ser propostas em face da União. (BRASIL. Supremo Tribunal Federal. 2019b).

Nesse julgamento, O STF admitiu o fornecimento excepcional de medicamento não registrado na Anvisa - inclusive o uso off label -, em caso de demora do órgão para apreciar o pedido de registro (salvo em relação a medicamentos órfãos para doenças raras e ultrarraras) e desde que haja registro do medicamento em renomadas agências de regulação no exterior e,

\footnotetext{
${ }^{4}$ Paula Cristiane Silva complementa: o uso "off label" é quando um medicamento é utilizado para uma indicação diferente daquela que foi autorizada pelo órgão regulatório de medicamentos em um país, e para as quais não existem bases científicas adequadas. É o uso para uma indicação terapêutica não descrita em bula podendo também estar relacionado ao uso do medicamento em uma faixa etária diferente da recomendada.(SILVA, Paula Cristiane et al. Medicamentos e o uso "off label". Disponível em www.revistas.ufpr.br Acesso em 18 de ago. 2019. m. 12. n. 2 Curitiba: Visão acadêmica. jul-dez. 2011, p. 1)
} 
ainda, não exista substituto terapêutico registrado no Brasil. Ficou registrada também a vedação ao fornecimento de medicamento em fase absolutamente experimental.

Finalmente, registre-se que o STF determinou que as demandas de fornecimento de medicamento sem registro na ANVISA devem ser propostas contra da União.

\subsection{Medicamentos de alto custo.}

Conforme exposto acima, o STF impôs restrições e definiu regras para o fornecimento de medicamentos não registrados pela ANVISA. Contudo, a questão sobre os medicamentos de alto custo tem gerado vários embates no âmbito do STF.

Os medicamentos de alto custo combatem a maioria das doenças consideradas raras, ultrarraras ou medicamentos órfãos (aqueles em relação aos quais a indústria farmacêutica tem baixo interesse em desenvolver e comercializar).

Sobre o tema, o Supremo Tribunal Federal possui precedentes recentes no sentido de que a condenação judicial do Estado para fins de fornecimento de medicamento de alto custo não representa lesão à ordem pública apta a autorizar o deferimento de suspensão de segurança. Nesse sentido, registra-se, ilustrativamente, o julgamento do Agravo Regimental na Suspensão de Segurança 5.222, Rel. Min, Cármen Lúcia, Tribunal Pleno, cujo acórdão possui a seguinte ementa:

\footnotetext{
Agravo regimental na suspensão de segurança. Fornecimento de medicamento de alto custo. Spinraza. Ameaça de grave lesão à economia pública não demonstrada. Risco de morte da paciente. Dano inverso. Suspensão indeferida. Ausência de argumentos ou fatos novos capazes de infirmar a decisão recorrida. Agravo regimental ao qual se nega provimento.
}

Todavia, trata-se de questão ainda pendente de análise definitiva, na medida em que o STF reconheceu repercussão geral do tema no Recurso Extraordinário 566.471, Rel. Min. Marco Aurélio, porém ainda não julgou o mérito desse feito paradigmático. A questão constitucional debatida nesse processo reside em saber se o Estado tem o dever de fornecer medicamento de alto custo a portador de doença grave que não possui condições financeiras para comprá-lo. Eis a ementa do acórdão que reconheceu a repercussão geral do assunto (Tema 6): "SAÚDE - ASSISTÊNCIA - MEDICAMENTO DE ALTO CUSTO - 
FORNECIMENTO. Possui repercussão geral controvérsia sobre a obrigatoriedade de o Poder Público fornecer medicamento de alto custo" (BRASIL. SUPREMO TRIBUNAL FEDERAL. 2007).

O feito consta atualmente do calendário de julgamento do Supremo Tribunal Federal, com previsão de análise no dia 23/10/2019. Espera-se que, nessa data, a questão seja finalmente pacificada e a Suprema Corte fixe tese diretiva aos demais órgãos jurisdicionais acerca da condenação judicial para que o Estado forneça medicamento de alto custo.

\section{CONCLUSÃO}

A saúde configura o bem mais precioso do ser humano, digna de receber a tutela protetiva do Estado, tendo em vista que se consubstancia no direito indissociável à vida. $\mathrm{O}$ direito à saúde, constitucionalmente consagrado, consiste também em um dever do Estado em prestar saúde digna e eficaz à população, por meio de prestação universal e igualitária. Tratase de direito coletivo que deve ser atendido por meio de políticas públicas, em todos os níveis da Federação brasileira (União, estados, Distrito Federal e municípios), pelo Sistema Único de Saúde.

A Constituição Federal traz em seu bojo a garantia de tal direito a todos os cidadãos, sendo dever do poder público concretizá-lo, na busca do bem-estar social. Nos termos dos arts. 196 e 198 da Constituição Federal, a saúde "é direito de todos e dever do Estado" e "as ações e serviços públicos de saúde integram um sistema único" (o SUS). Contudo, em que

pese o mandamento constitucional de caráter programático, o direito à saúde esbarra na escassez de recursos e na escolha de prioridades da Administração Pública.

Tendo em vista a contínua e reiterada omissão do Estado em garantir uma saúde digna aos cidadãos, o fenômeno da judicialização da saúde tem gerado aumento considerável do número de demandas requerendo ao poder Judiciário a concessão de medicamentos e procedimentos médicos.

Não pairam dúvidas de que o fenômeno da judicialização gera impacto substancial no orçamento público, na medida em que o Judiciário se torna realizador de políticas públicas. Mas como falar em igualdade, no sentido de dar efetividade à saúde? Se o Judiciário assume o

\section{Revista de Direito Sociais e Políticas Públicas | e-ISSN: 2525-9881 | Belém | v. 5 | n. 2 |}

p. 23 - 42 | Jul/Dez. 2019. 
protagonismo na efetivação do direito à saúde, estaria esse Poder necessariamente efetivando o SUS?

A proteção dos direitos fundamentais deve ser efetuada com vistas no princípio da dignidade da pessoa humana, afinal, a saúde deve ser concebida como um direito universal, em favor de todo cidadão. A Lei 8.080/90, além de estruturar o SUS e de fixar suas atribuições, dispõe sobre os princípios em que sua atuação deve orientar-se, destacando-se o princípio da universalidade, o qual deve garantir a todas as pessoas o acesso às ações e serviços de saúde disponíveis.

O Sistema Único de Saúde representa um grande avanço no tocante às políticas públicas, uma vez que está baseado no financiamento público, bem como na cobertura universal das ações à saúde. Entretanto, a legislação do SUS deve ser efetivamente utilizada, fazendo com que tal lei saia do papel e seja aplicada na prática.

Indubitavelmente que deve ser reconhecido o avanço trazido pela Constituição Federal de 1988 no tocante ao direito à saúde. Contudo, deve-se buscar o aprimoramento das políticas públicas promovidas pelo SUS.

Torna-se necessária a busca pela expansão efetiva do direito social à saúde, no intuito de se alcançar um sistema de saúde mais justo, igualitário e universal. Mas, para isso cabe ao Estado (nos três entes da federação) formular e implementar políticas públicas que garantam a efetividade do Direito à saúde, tendo em vista, principalmente a existência de conflitos entre os preceitos constitucionais e fatores relacionados às desigualdades sociais, problemas orçamentários e éticos, bem como interesses econômicos.

Desse modo, cabe ao Estado implementar políticas públicas adequadas para o setor da saúde (prevenção, tratamento e controle de doenças), assegurando a todos o acesso universal e igualitário, por meio de políticas de saúde que propiciem condições de estruturação de um sistema que garanta o real e efetivo acesso aos serviços de saúde para a população.

Nessa conjuntura, o direito fundamental à saúde deve ser garantido pelos Estados aos seus cidadãos, por meio de políticas e ações públicas que permitam o acesso aos meios adequados ao bem-estar físico, mental e social.

No que tange à judicialização da saúde, nota-se que há posicionamentos contrários e a favor. Aqueles que se posicionam de forma contrária defendem que o processo de judicialização representa uma interferência indevida do Judiciário na atuação dos poderes 
Executivo e Legislativo; entendem, inclusive, que o SUS é capaz de garantir a eficácia do direito positivado posicionamente.

Por outro lado, os que defendem a judicialização, partem do pressuposto de que é imprescindível a atuação do poder Judiciário para a concretização do Direito à Saúde, principalmente nos casos em que o Estado é omisso no seu dever de prestação estabelecido na Constituição. Ora, diante da omissão estatal, a única opção do cidadão é recorrer ao Judiciário, na busca do reconhecimento de sua dignidade e pelos seus direitos constitucionais.

Nesse contexto, urge salientar que o fenômeno da judicialização gera impacto substancial no orçamento público e nos programas de governo, de modo que é preciso estabelecer um ponto de equilíbrio entre os direitos sociais fundamentais dispostos na Constituição e as limitações orçamentárias alegadas pelo ente estatal, sendo razoável estabelecer critérios e parâmetros a efetivação judicial do direito à saúde.

Um dos maiores desafios enfrentados pela população brasileira é a dificuldade de acesso a medicamentos. Nesse contexto, a jurisprudência dos tribunais superiores, especialmente do Superior Tribunal de Justiça e do Supremo Tribunal Federal, tem apresentado algumas soluções.

O Superior Tribunal de Justiça definiu algumas premissas necessárias ao fornecimento de medicamento de alto custo pelo Estado, como inexistência de outro medicamento incorporado ao SUS que tenha a mesma eficiência terapêutica que o medicamento pleiteado e o seu efetivo registro na ANVISA, o que obstava o fornecimento de medicamento para uso off label.

Após essa decisão, o STF admitiu o fornecimento excepcional de medicamento não registrado na Anvisa - inclusive o uso off label -, em caso de demora do órgão para apreciar o pedido de registro (salvo em relação a medicamentos órfãos para doenças raras e ultrarraras) e desde que haja registro do medicamento em renomadas agências de regulação no exterior e, ainda, não exista substituto terapêutico registrado no Brasil. Ficou registrada também a vedação ao fornecimento de medicamento em fase absolutamente experimental.

Finalmente, registre-se que o STF determinou que as demandas de fornecimento de medicamento sem registro na ANVISA devem ser propostas contra da União.

No que tange aos medicamentos de alto custo, o Supremo Tribunal Federal possui precedentes recentes no sentido de que a condenação judicial do Estado para fins de fornecimento de medicamento de alto custo não representa lesão à ordem pública apta a 
autorizar o deferimento de suspensão de segurança. Todavia, trata-se de questão ainda pendente de análise definitiva, na medida em que o STF reconheceu repercussão geral do tema no Recurso Extraordinário 566.471, Rel. Min. Marco Aurélio, porém ainda não julgou o mérito desse feito paradigmático.

À guisa de conclusão, evidencia-se que crescem assustadoramente os desafios na relação entre o Estado, a sociedade e o Judiciário no processo de efetivação do direito à saúde. O Judiciário tenta estabelecer parâmetros, no intuito de assegurar um direito à saúde que realmente se coadune com os mandamentos constitucionais.

\section{REFERÊNCIAS E BIBLIOGRAFIA}

ACHOCHE, M. S. A garantia constitucionalmente assegurada do direito à saúde e o cumprimento das decisões judiciais . Jus Navigandi, Teresina, ano 13, n. 2102, 3 abr. 2009. Disponível em: <http://www.jus.com.br> Acesso em: 24 jul. 2009.

ANDRADE, V. V. H. Curso jurídico de Direito à Saúde. Belo Horizonte: EJEF, 2015.

ANS. Agência Nacional de Saúde Suplementar. Cadernos de Informações da Saúde Suplementar, agosto de 2010.

APPIO, E. Controle Judicial das Políticas Públicas no Brasil. Curitiba: Juruá, 2005.

ARAÚJO, L. A. D.; NUNES JÚNIOR, V.S. Curso de direito constitucional. 3. ed. São Paulo: Saraiva, 2007.

Theorie der Grundrechte.4. ed. Suhrkamp: Baden-Baden, 2001.

BAHIA, L. Sistema único de saúde. Disponível em <http://www.epsjv.ficruz.br.htm>. Acesso em 11 jan. 2013.

BARROS, S. R. de. Direitos Humanos: paradoxo da civilização. Belo Horizonte: Del Rey, 2003.

BARROSO, L. R. Interpretação e aplicação da Constituição. 6. ed. São Paulo: Saraiva, 2004.

Ponderação, racionalidade e atividade jurisdicional. In. BARROSO, L. R. A

reconstrução democrática do direito público no Brasil. Rio de Janeiro : Renovar, 2007.

Da falta de efetividade à judicialização excessiva: direito à saúde, fornecimento gratuito de medicamentos e parâmetros para a atuação judicial. Disponível em <http://www.migalhas.com.br.htm> Acesso em 10 jan. 2013. 
BISOTO JR., G.; SILVA, P. L. de B; DAIN, S. (orgs.) Regulação do setor saúde nas Américas: as relações entre o público e o privado numa abordagem sistêmica. Brasília: Organização Pan-Americana da Saúde, 2006.

BONAVIDES, P. Curso de Direito Constitucional. 10. ed. São Paulo: Malheiros, 2008.

BOTTESINI, M. A.; MACHADO, M. C. Lei dos planos e seguros de saúde: comentada artigo por artigo. 2.ed. São Paulo: Revista dos Tribunais, 2005.

BULOS, U. L. Curso de Direito Constitucional. 6.ed. São Paulo: Saraiva, 2011.

CANOtilho, J. J. Gomes. Direito Constitucional e teoria da Constituição. 4. ed.

Coimbra: Almedina, 2000.

CARVALHO, K.G. Direito Constitucional. 18. ed. Belo Horizonte: Del Rey, 2012.

CASTRO,E. K. A teoria da reserva do possível e sua utilização pelo judiciário nas demandas de saúde no Brasil. Revista de Direito. V. 8. N. 01, p. 63-83, Viçosa, 2016. Disponível em https: //revistadir.ufv.br Acesso em 02 jan. 2019)

CORREIA, S. Introdução ao direito à saúde. In. Direito da saúde e bioética. Lisboa: LEX, 1991.

COSTA, I. G. Aplicação dos princípios da reserva do possível e do mínimo existencial no fornecimento de medicamentos. Revista IOB de Direito Administrativo. v. 5. n. 54. São Paulo: IOB, jun. 2010.

CUETO, M. O valor da saúde: história da Organização Pan-Americana da Saúde. Trad. Vera Ribeiro. Rio de Janeiro: Fiocruz, 2007

CUNHA, J.P.P., CUNHA, R.E. Sistema Único de Saúde - SUS: princípios. In: CAMPOS, F.E., OLIVEIRA JÚNIOR, M., TONON, L.M. Cadernos de Saúde. Planejamento e Gestão em Saúde. Belo Horizonte: COOPMED, 1998. Cap.2, p. 11-26.

DALlARI, S. G. Competência municipal em matéria de saúde. Revista de Direito Público. N. 92, São Paulo, 1989.

Normas gerais sobre saúde: cabimento e limitações. Disponível em:

<www.saude.caop.mp.br>. Acesso em 16 de ago. 2013.

DEOTTI, B. et al. Evidência científica: ensino, produção e reflexão. Rio de Janeiro: Autografia, 2017.

DIMOULIS, D.; MARTINS, L. Teoria dos direitos fundamentais. São Paulo Revista dos Tribunais, 2011. 
DORES, C. J. Controle judicial de políticas públicas de saúde. Disponível em <http://www.jus.com.br/revista.html> . Acesso em 19 mar 2013. p. 01.

DRESCH, R. L. A judicialização da saúde e a racionalização das decisões judiciais. In. CANCHERINI, C.E.; SOUSA, S. L. S. e. Estudos em homenagem à Desembargadora Vanessa Verdolim Hudson Andrade (Org.). Belo Horizonte: Del Rey, 2106.

DRESCH, R. L.; BICALHO, Fábia Madureira de Castro. Manual de direito à saúde: normatização e judicialização. Comitê Executivo da Saúde de Minas Gerais. Belo Horizonte: Del Rey, 2019.

ELIAS, P. E. Estado e saúde: os desafios do Brasil contemporâneo. Revista São Paulo em Perspectiva. vol.18 no.3 São Paulo July/Sept. 2004.

FARENA, D. V. M. A saúde na Constituição Federal. In: Boletim do Instituto Brasileiro de Advocacia Pública, n. 4, 1997.

FIGUEIREDO, M. F. Direito fundamental à saúde: parâmetros para sua eficácia e efetividade. Porto Alegre: Livraria do Advogado, 2007.

FREIRE JÚNIOR, A. B. O controle judicial de políticas públicas. 2004. 117 f. Dissertação (Mestrado em Direito e Garantias Constitucionais Fundamentais) - Faculdades de Vitória, Vitória, 2004. Disponível em: < http://www.dominiopublico.gov.br/download/teste/arqs/cp098343.pdf>. Acesso em: 7 abr. 2014.

GERSCHMAN, S. Políticas comparadas de saúde suplementar no contexto de sistemas públicos de saúde: União Europeia e Brasil. Revista Ciência e saúde coletiva. vol.13 no.5 Rio de Janeiro, Set./Out. 2008.

GRAU, E. R. Ensaio e discurso sobre a interpretação-aplicação do direito. São Paulo: Malheiros, 2001.

GREGORY, M. S. Planos de saúde: a ótica da proteção do consumidor. 2.ed. São Paulo: Revista dos Tribunais, 2010.

HUMENHUK, H. O direito à saúde no Brasil e a teoria dos direitos fundamentais. Jus Navigandi, Teresina, ano 9, n. 227, 20 fev. 2004. Disponível em:

<http://jus.uol.com.br/revista/texto/4839.htm>. Acesso em: 09 nov. 2010.

KUJAWA, H. A questão da saúde no Brasil. Disponível em <http://www.ceadp-rs.org. br.htm> . Acesso em 20 jul 2010.

CANUT, L. In Assistência complementar à saúde $\mathbf{X}$ assistência suplementar à saúde. Disponível em www.odireitosanitário.blogspot.com 
LIMA, L. T. B. Um novo modelo para o serviço público de saúde brasileiro. Ano 10. N.

LIMA, R. S. de F. Direito à saúde e critérios de aplicação. In SARLET, I. W; TIMM, L. B (Org.). Direitos fundamentais, orçamento e reserva do possível. Porto Alegre: Livraria do Advogado, 2008.

LIMBERGER, T.; GRISON, L. Políticas públicas de direito à saúde: a necessidade de critérios hermenêuticos para a intervenção judicial. Revista Estudos Jurídicos. ISSN Eletrônico 2175-0491, Santa Cruz do Sul: 2010.

LIPPEL, A. G. O direito à saúde na Constituição de 1988: caracterização e efetividade. Disponível em: <http:// www.revistadoutrina.trf4.gov.br.htm> Acesso em: 07 dez 2006.

LUCHESE, P. Introdução: Políticas Públicas em Saúde. Disponível em:

<http://www.ppge.ufrgs.br.htm> Acesso em 18 mar 2013.

MACERA, A. P.; SAINTIVE, M. B. O mercado de saúde suplementar no Brasil. Brasília: SEAE/MF, 2004.

MAGALHÃES JR., H. M. Regulação assistencial: a busca de novas ferramentas no SUS para enfrentar o desafio de garantir a assistência com equidade. Belo Horizonte: Prefeitura Municipal, 2002. (Pensar BH - política social).

O desafio de construir e regular redes públicas com integralidade em sistemas privado-dependentes: a experiência de Belo Horizonte. 2006. Tese (Doutorado) - Faculdade de Ciências Médicas, Universidade de Campinas, Campinas.

MAGAlhãeS, J. Q. de. Direito Constitucional. Curso de Direitos Fundamentais. 3ed. ver. e atual. São Paulo: Método, 2008.

MARQUES, M. A. F.; SOUSA, S. L. S. e. O direito fundamental à saúde e a medicina baseada em evidências - BEM como instrumento de verificação da (im)possibilidade de fornecimento da fosfoetanolamina na via judicial. In Direito e Política Públicas III. XXV Encontro Nacional do CONPEDI, Brasília: DF, 2016.

MARQUES, 2015, 635/636. DIREITO, CONSTITUIÇÃO E CIDADANIA: contribuições para os objetivos de desenvolvimento do Milênio. Disponível em <http://www.conpedi.org.br/publicacoes/c178h0tg/rma2ey1m/eO2Fy1FK8omZQ99g.pdf>. Acesso em 14.05.2016).

MARTINS. W. Direito à saúde. Belo Horizonte: Fórum, 2008.

NASCIMENTO, A. F. do. Direito à saúde deve ser visto em face do princípio da reserva do possível. Disponível em www.conjur.com.br Acesso em 22/05/2019. 
NUNES, F.P. Pluralismo jurídico e a participação popular em saúde: do público ao provado. Dissertação apresentada no Curso de Pós Graduação em Direito da Universidade Federal de Santa Catarina. Florianópolis, abril, 2011.

OHLAND, L. Responsabilidade solidária dos entes da Federação no fornecimento de medicamentos. v. 36. N. 1. Porto Alegre: Direito e Justiça, 2010.

ORDACGY, A. da S. A tutela de direito de saúde como um direito fundamental do cidadão. Disponível em http//:www.dpu.gov.br/pdf/artigos/artigo-saude-andre.pdf Acesso em 02 jan. 2019.

PEREIRA, E. A.; HUSSNE, R. D. Regulação e Padrão Competitivo no Setor de Saúde Suplementar. Revista Brasileira de Risco e Seguro. Rio de Janeiro, v. 6, n. 12, p. 17-36, out. 2010/mar. 2011.

PINTO, E. G. Financiamento do Direito à Saúde e à Educação - uma perspectiva constitucional. Belo Horizonte: Fórum, 2017.

SAMPAIO, G. J. M. de C. O Estado regulador. Dissertação de mestrado apresentada na Universidade de São Paulo, São Paulo: USP, 2007.

SARLET, I. W. A eficácia dos direitos fundamentais. São Paulo: Malheiros, 2006-2007.

SARLET, I. W.; FIGUEIREDO, M. F. Algumas considerações em torno do conteúdo, eficácia e efetividade do direito à saúde na Constituição de 1988. Disponível em <http://www.direitodoestado.com.br.htm> . Acesso em 20 dez 2012.

SARLET, I. W.; FIGUEIREDO, M. F. Reserva do possível, mínimo existencial e direito à saúde: algumas aproximações. Revista de Doutrina da $4^{\text {a }}$ Região, Porto Alegre, n. 24, jul. 2008. Disponível em:

<http://www.revistadoutrina.trf4.jus.br/artigos/edicao024/ingo_mariana.html> Acesso em:16 mar. 2014.

SCAFF, F. F. Reserva do Possível, Mínimo Existencial e DireitosHumanos. Porto Alegre: Notadez, 2005.

SILVA, L. P. Direito à saúde e o princípio da reserva do possível. Disponível em:http://www.stf.jus.br/arquivo/cms/processoAudienciaPublicaSaude/anexo/DIREITO_A_S AUDE_por_Leny.pdf. Acesso em: 20 maio 2011.

SILVA, P. C. et al. Medicamentos e o uso "off label". Disponível em www.revistas.ufpr.br Acesso em 18 de ago. 2019. m. 12. n. 2 Curitiba: Visão acadêmica. jul-dez. 2011.

SILVA, R. A. D. da. Direito fundamental à saúde: o dilema entre o mínimo existencial e a reserva do possível. Belo Horizonte: Fórum, 2010.

SOUSA, S. L. S. e. Direito à saúde e políticas públicas. Belo Horizonte: Del Rey, 2015. 
TAVARES, A. Métodos e técnicas de planejamento em saúde. Lisboa: Ministério da Saúde - Departamento de Recursos Humanos de Saúde, 1990.

URBANO, H. E. M. C. Notas sobre a efetivação do direito fundamental à saúde. Revista de Informação Legislativa. Brasília, 47 n. 188 out./dez. 2010.

VALLE, G. H. M. do; CAMARGO, J. M. P. A audiência pública sobre a judicialização da saúde e seus reflexos na jurisprudência do Supremo Tribunal Federal. Revista de Direito Sanitário, São Paulo, v. 11, n. 3, p.13-31, 01 nov. 2010. Disponível em: http://pesquisa.bvsalud.org/portal/resource/pt/cid-64302. Acesso em: 08 ago. 2019.

VENTURA, M. et al. Judicialização da saúde,acesso à justiça e a efetividade do direito à saúde. Rio de Janeiro: Physis, v. 20, n. 1, p. 77-100, 2010.

VIEIRA, W. M. Direito à saúde: compêndio. Belo Horizonte: Fórum, 2008.

WEICHERT, M. A. Saúde e Federação na Constituição Brasileira. Rio de Janeiro: Lumen Juris, 2004. 